\title{
I 4.3 Early cardiovascular risk assessment in patients with juvenile idiopathic arthritis
}

\author{
AP Vlahos*1, S Alfantaki ${ }^{3}$, A Bechlioulis ${ }^{2}$, K Vakalis ${ }^{2}$, LK Michalis ${ }^{1}$ and \\ A Siamopoulou ${ }^{1}$
}

\author{
Address: ${ }^{1}$ University of Ioannina, Ioannina, Greece, ${ }^{2}$ Michaelidion Cardiac Centre, Universtiy of Ioannina, Ioannina, Greece and ${ }^{3}$ University \\ Hospital of Ioannina, Ioannina, Greece \\ * Corresponding author
}

\author{
from 15th Paediatric Rheumatology European Society (PreS) Congress \\ London, UK. 14-17 September 2008 \\ Published: 15 September 2008 \\ Pediatric Rheumatology 2008, 6(Suppl I):S30 doi:I0.I I86/I546-0096-6-SI-S30
}

This abstract is available from: http://www.ped-rheum.com/content/6/SI/S30

(c) 2008 Vlahos et al; licensee BioMed Central Ltd.

\section{Background}

Inflammation has emerged as an important factor that contributes to the development of atherosclerosis and is associated with increased cardiovascular risk. Juvenile idiopathic arthritis (JIA) is a chronic inflammatory condition with its origin in childhood. Its adult form, rheumatoid arthritis, has been associated with an excess of cardiovascular disease even after adjustment for traditional risk factors.

\section{Materials and methods}

Arterial stiffness indices were measured, noninvasively. Pulse Wave Velocity (PWV) and Augmentation Index (AIx) were calculated using the Shpygmocor device (AtCor Medical, Sydney, Australia). Vascular Compliance was determined as a function of both the arterial system's capacitance (C1) and that of the reflectance or oscillatory (C2) function using the HDI/PulseWave CR-2000 (Hypertension Diagnostics, Inc., Eagen, MN). The cardiac diastolic function was assessed using classic, tissue Doppler and colour M-mode echocardiography.

\section{Results}

There were 33 patients with JIA (25 F, $8 \mathrm{M}$ ) aged $13 \pm 6$ years with 6 years mean duration of the disease that were compared with 22 controls ( $13 \pm 3$ years) matched for age and gender. Among the indices assessed a significant difference was found regarding the AIx $(\mathrm{p}=0.006)$ and the $\mathrm{C} 1$ ( $\mathrm{p}=0.029)$ of the patients, indicating increased vascu- lar stiffness compared to controls. There was no difference in the cardiac diastolic function in respect to all indices assessed.

\section{Conclusion}

Early manifestations of vascular dysfunction are evident in patients with JIA from childhood. Cardiac diastolic dysfunction appears to be a later finding in this patient group. Since vascular stiffness is an early finding this may necessitate appropriate pharmaceutical and lifestyle intervention. 